PALABRAS CLAVE

Política fiscal

Administración fiscal

Hacienda pública

Leyes y reglamentos

Instituciones financieras

internacionales

Estudios de casos

Evaluación

Argentina

Miguel Braun

Director de Políticas,

Centro de Implementación de

Políticas Públicas

para la Equidad y el Crecimiento

(CIPPEC),

Argentina

œmbraun@cippec.org

Nicolás Gadano

Investigador Asociado,

CIPPEC

Profesor de la Maestría en Políticas Públicas,

Universidad Di Tella,

Argentina

œngadano@fibertel.com.ar
REVISTA DE LA CEPAL 91 - ABRIL 2007

\section{¿Para qué sirven las reglas fiscales? Un análisis crítico de la experiencia argentina}

\author{
Miguel Braun y Nicolás Gadano
}

$\mathrm{E}$

ste artículo presenta una visión crítica de la utilidad de aplicar leyes de responsabilidad fiscal en entornos de baja institucionalidad. Analiza el caso argentino, donde el uso pródigo de reglas fiscales — dos leyes distintas en tan solo cinco años- contrasta con su limitada eficacia para asegurar la sustentabilidad de la política fiscal y mejorar la transparencia, y verifica que en situaciones de debilidad institucional es difícil que una ley de responsabilidad fiscal limite las decisiones de los gobernantes hasta el punto de corregir el comportamiento de las finanzas públicas. El caso argentino aparece entonces como un llamado de atención para aquellos que promueven la implementación de reglas fiscales. Cuando existe baja reputación fiscal e institucionalidad débil, las reglas no solamente pueden resultar ineficaces en materia fiscal, sino que su incumplimiento puede deteriorar más el frágil contexto institucional que dificulta su eficacia. 


\section{Introducción}

“Era tan dulce la voz que no pude resistir el deseo de oírla de más cerca
e hice señas a mis compañeros de que me desataran. Pero, siguiendo
las instrucciones que por anticipado les di, me ataron al mástil más
fuertemente con nuevos cordeles”.

Homero, La Odisea, Canto XII. ${ }^{1}$

Tanto en los estudios teóricos como en las recomendaciones de organismos internacionales ha surgido una creciente fe en las reglas fiscales como instrumentos para contribuir a la solvencia fiscal en países en desarrollo. El argumento teórico evoca la escena de Ulises y las sirenas citada arriba, en la que Ulises le pide a sus marineros que lo aten al mástil para evitar la tentación del canto de las sirenas. Las reglas son vistas como límites legales e institucionales que impedirían el comportamiento oportunista de políticos que buscan gastar de más. En particular, las reglas vendrían a contrarrestar el sesgo hacia el déficit fiscal que implican los problemas de propiedad común de los recursos públicos, los de principal-agente y los de inconsistencia temporal identificados en las publicaciones recientes de economía política. ${ }^{2}$

El argumento es una aplicación del principio de reglas contra la discrecionalidad elaborado por Kydland y Prescott (1977), y encuentra un paralelo en el debate a favor de la independencia del Banco Central en el manejo de la política monetaria. ${ }^{3}$ Kopits (2001), por ejemplo, sostiene que la principal utilidad de contar con un conjunto de reglas fiscales permanentes, bien diseñadas y adecuadamente implementadas, para evitar un sesgo deficitario es que este establece un marco despolitizado para la política fiscal, similar a la despolitización de la política monetaria bajo un régimen de metas de inflación.

En América del Sur se han dictado leyes de responsabilidad fiscal, por ejemplo, en Brasil, Chile y Argentina. En Brasil y Chile han sido — al menos hasta

$\square$ Los autores agradecen la asistencia en la investigación de Ariel Dvoskin y los comentarios de Juan Pablo Jiménez y Cynthia Moskovitz.

1 Versión de Editorial Akal (Homero, 1987).

${ }^{2}$ Véase Drazen (2002) y Persson y Tabellini (2000), dos textos recientes que resumen esta literatura.

${ }^{3}$ Por ejemplo, véase Cukierman (1992). ahora- relativamente exitosas en materia de solvencia fiscal, lo que sus partidarios consideran una comprobación de sus argumentos Sin embargo, en Argentina los resultados han sido débiles, si no nulos, y el debate no parece arrojar luz sobre la causa de esa diferencia.

A nuestro entender, el argumento a favor de las leyes de responsabilidad fiscal expuesto en los dos primeros párrafos de esta introducción está insuficientemente especificado. Creemos indispensable la indicación expresa de que los países que establecen legislación sobre responsabilidad fiscal deben tener instituciones suficientemente fuertes como para que i) la formulación de las reglas fiscales sea precisa, sin dar lugar a interpretaciones que desnaturalicen sus objetivos y ii) la aplicación de tales reglas sea rigurosa y coherente con sus disposiciones, de modo que ni el Poder Ejecutivo nacional ni las autoridades jurisdiccionales menores actúen a sus espaldas.

$\mathrm{El}$ argumento de Kopits, por ejemplo, se refiere a este tema, pero no hace una advertencia clara de que las condiciones que describe no pueden suponerse satisfechas sin más: antes de lanzarse a aprobar una ley de responsabilidad fiscal es necesario verificar que esas condiciones se han cumplido, y encarar las mejoras y cambios necesarios. En las páginas que siguen mostraremos con detalle que, en la época en que comenzaron a considerarse y aplicarse reglas fiscales en la región, Argentina era precisamente un caso de contexto institucional inapropiado para ponerlas en práctica con éxito.

Más aún, en el caso argentino, según se mostrará, las reglas fiscales aprobadas han sido más bien una respuesta a problemas de la coyuntura político-económica antes que mecanismos destinados a contribuir de manera permanente a la solvencia fiscal. El incumplimiento de esas reglas no solo ha puesto de manifiesto la incapacidad de las leyes de responsabilidad fiscal por sí solas 
para mejorar el desempeño fiscal con independencia del contexto institucional, sino que ha contribuido a profundizar la fragilidad de las instituciones y el descrédito social del sistema legal.

A continuación, en la sección II se resume la literatura reciente vinculada a la eficacia de las reglas fiscales. En la sección III se examina la experiencia de Argentina con la implementación de reglas fiscales previa a la aprobación de las leyes de responsabilidad, para luego analizar su contenido en la sección IV. Finalmente, la sección V presenta algunas conclusiones.

\section{II}

\section{¿Qué son las reglas fiscales y para qué sirven?}

Antes de seguir adelante necesitamos una definición operativa de las reglas fiscales. Seguiremos a Kopits y Symansky (1998), para quienes una regla fiscal es una restricción permanente (o duradera) de la política fiscal, que se expresa a través de indicadores de los resultados fiscales, como el déficit fiscal, el nivel de deuda o algún componente del gasto. Cuando hablamos de reglas fiscales en este trabajo, nos estamos refiriendo a reglas numéricas. Esta aclaración es importante, pues muchos estudios utilizan una definición más amplia de las reglas fiscales e incluyen en ella las reglas de procedimiento, que regulan el proceso decisorio en torno a la política fiscal, y las reglas de transparencia, que determinan las obligaciones de hacer pública la información fiscal. ${ }^{4}$

Los mismos autores sostienen que algunas de las variables clave son: el objetivo numérico específico al que apunta la regla (debe ser claro, medible y lo más amplio posible); el período de aplicación de la norma (cuanto más largo mejor); los instrumentos legales utilizados (de la mayor jerarquía posible, idealmente de carácter constitucional), el nivel de gobierno al que se aplican (cuanto más ampliamente mejor) y los castigos por incumplimiento (cuanto más duros mejor, idealmente llegando incluso a la responsabilidad penal de los funcionarios). Las reglas suelen incluir también las llamadas "cláusulas de escape", es decir, mecanismos de flexibilización contingente dirigidos a evitar efectos procíclicos indeseados.

Las razones para justificar el establecimiento de este tipo de reglas surgen de la literatura reciente de economía política. Esta literatura atribuye las diferencias de comportamiento fiscal entre países con similar

\footnotetext{
${ }^{4}$ Véase, por ejemplo, Alesina y Perotti (1996). Las llamadas "reglas de procedimiento" se emparentan con lo que históricamente ha sido la normativa asociada a la administración financiera pública.
}

situación económica a disparidades de las instituciones y prácticas políticas. Según Tommasi (1998), los problemas de economía política que influyen en los resultados fiscales se pueden agrupar en dos grandes categorías: los problemas de principal-agente y los problemas de cooperación.

En el primer grupo se encuentran los problemas que surgen del carácter delegatorio del sistema de gobierno. Los votantes eligen a sus representantes y delegan en ellos la facultad de tomar decisiones de interés público. Como la información es asimétrica y los intereses de los representantes no siempre coinciden con los de los representados, las políticas pueden diferir de las más deseables. Un ejemplo en el caso fiscal es la tendencia de los gobiernos a aumentar el gasto en años de elecciones. ${ }^{5}$

Los problemas de cooperación, en cambio, son aquellos que emanan de la interacción de diversos grupos nacionales y subnacionales que pugnan por recursos públicos, generando una tendencia al gasto y al endeudamiento excesivos. Un ejemplo clásico proviene de Weingast, Shepsle y Johnsen (1981) y muestra que el gasto público puede aumentar debido al problema de pozo común inherente a la interacción política de regiones con representación parlamentaria. Según estos autores, los legisladores tienen incentivos para proponer aumentos de gasto que beneficiarían a su región porque los recursos surgen de la recaudación tributaria que se realiza en todo el país. Velasco (1999) analiza el problema de pozo común en un contexto dinámico y muestra cómo puede llevar a mayores déficit y niveles de endeudamiento.

Tabellini y Alesina (1988) explican el déficit fiscal a partir de la inconsistencia temporal (es decir, la falta

\footnotetext{
${ }^{5}$ Véase un examen reciente del tema en Drazen y Brender (2005).
} 
de coherencia en el tiempo de las decisiones), asociada a posibles discrepancias entre las preferencias de los votantes del presente y del futuro, y a la incapacidad de los primeros para limitar las decisiones de los segundos. En este escenario, los votantes del presente tienden a impulsar niveles de gasto y déficit que exceden los que son óptimos para la sociedad en su conjunto.

Los trabajos mencionados en el comienzo de esta sección atribuyen los diferentes resultados fiscales de países, con similares condiciones e instituciones económicas, a diferencias en las instituciones y las prácticas políticas. En particular, los problemas de cooperación, de inconsistencia temporal y de principal-agente que influyen en los resultados fiscales pueden variar en distintos países y diferentes períodos de tiempo, debido a cambios en las instituciones políticas que afectan los incentivos de quienes más influyen en los resultados fiscales. Por ejemplo, Alesina y Perotti (1996) sostienen que cuando el proceso presupuestario de un país es más jerárquico —el Poder Ejecutivo pesa más que el Poder Legislativo, y el Ministerio de Hacienda más que los otros ministerios- la solvencia fiscal es mayor. Esto se debe a que el Presidente y el ministro de Hacienda internalizan más que el Congreso y los ministros sectoriales la restricción presupuestaria intertemporal del gobierno y, por lo tanto, cuidan más los resultados fiscales.

Estos argumentos están detrás de la defensa de las reglas fiscales como mecanismo para mejorar la solvencia fiscal. Cuando los actores políticos tienen incentivos para gastar de más, o la dinámica no cooperativa lleva a un exceso de gasto, la existencia de una regla numérica que ponga un tope al gasto, al déficit o al endeudamiento permitiría obtener mejores resultados que la ausencia de esa regla. Desde luego, el supuesto básico detrás de este análisis es que la regla se cumple. ${ }^{6}$

\footnotetext{
${ }^{6}$ Hay también algunas voces críticas en la literatura. Milesi-Ferretti (2000), por ejemplo, sostiene que las reglas numéricas pueden llevar a los gobiernos a incurrir en lo que se conoce como "contabilidad creativa" — es decir, alterar la medición de las cuentas públicas para reflejar un resultado numérico que cumpla con la regla-, cuando la meta fijada en la regla es muy exigente comparada con la situación fiscal y cuando el nivel de transparencia presupuestaria es bajo.
}

Sin embargo, no es fácil encontrar evidencia empírica convincente acerca del efecto de las reglas sobre los resultados fiscales. Braun y Tommasi (2004) sostienen que los cambios en las reglas fiscales no son comunes a nivel nacional, y que cuando ocurren, suelen ir acompañados por otras reformas que afectan los resultados fiscales, lo cual complica el ejercicio de asignar la responsabilidad por los cambios fiscales a las modificaciones de las reglas. Este problema limita el potencial explicativo de regresiones de series de tiempo dentro de un país, y de regresiones con datos de varios países, ya que habría pocas observaciones; por lo demás, una correlación entre cambios en las reglas y cambios en los resultados que no tome en cuenta otras reformas estaría sesgada.

Ante los resultados heterogéneos observados tras la aplicación de reglas fiscales, algunos autores han sugerido que esas reglas, para tener éxito, deben contar con un fuerte respaldo político. ${ }^{7} \mathrm{Si}$ este fuera el caso, sin embargo, deberíamos preguntarnos si no es precisamente ese respaldo político a la disciplina fiscal el que provoca la mejora en el desempeño de las finanzas públicas, con independencia del establecimiento de reglas formales. ${ }^{8}$ En esta línea de razonamiento, las leyes de responsabilidad fiscal serían simplemente un vehículo para construir consensos sociales en torno a la importancia de la disciplina fiscal. Sin ese consenso, la sola presencia de las reglas no aseguraría ninguna mejora en el comportamiento de las finanzas públicas.

La falta de evidencia empírica contundente que respalde la utilidad de las reglas para mejorar los resultados fiscales no nos sorprende a la luz de lo sucedido en Argentina. ${ }^{9}$ En la próxima sección se describe la experiencia argentina con las reglas fiscales, haciendo hincapié en la Ley de responsabilidad fiscal de 2004, sancionada en la primera mitad del año indicado.

\footnotetext{
${ }^{7}$ Véase Schick (2002) y Ter-Minassian (2006).

${ }^{8} \mathrm{Si}$ el establecimiento formal de reglas refleja las preferencias de los votantes por la prudencia fiscal, entonces la correlación entre reglas y prudencia fiscal sufriría del sesgo de variable omitida. La literatura académica reciente ha intentado resolver estos problemas de identificación, sin mucho éxito hasta el momento.

${ }^{9}$ Véase un análisis de la Ley de responsabilidad fiscal de 1999 en Gadano (2003).
} 


\title{
III
}

\section{Las reglas fiscales en Argentina}

\author{
"Hegel comenta en algún lado que todos los grandes hechos históricos \\ y personajes mundiales ocurren dos veces. Se olvidó de agregar: \\ la primera vez como tragedia y la segunda como farsa”.
}

Karl Marx, El dieciocho brumario de Luis Bonaparte. ${ }^{10}$

Durante la década de 1990, Argentina pasó por un proceso de transformación de su sistema de administración financiera pública, cuyo elemento principal fue la sanción de una nueva ley de Administración Financiera Pública (la ley 24.156 de septiembre de 1992), que redefinió los roles y procedimientos en la hacienda pública nacional, así como el funcionamiento de los organismos de fiscalización. Estructurada sobre la base del principio de centralización normativa y descentralización operativa, la reforma estableció el rol rector de la Secretaría de Hacienda, delegando al mismo tiempo en las distintas jurisdicciones y entidades el proceso cotidiano de gestión presupuestaria. La Sindicatura General de la Nación (SIGEN) quedó a cargo de la fiscalización interna dentro del Poder Ejecutivo, mientras que el control externo fue asignado a la Auditoría General de la Nación, un organismo dependiente del Congreso Nacional. ${ }^{11}$

Según los trabajos sobre las reglas fiscales, el proceso de reforma impulsado por la ley 24.156 no incorporó reglas fiscales cuantitativas a la administración financiera pública, sino que se concentró en las llamadas "reglas de procedimiento", es decir, en la normativa que regula los procesos presupuestarios y de administración de los recursos públicos.

La introducción de reglas fiscales de carácter numérico comenzó a discutirse en la segunda mitad del decenio de 1990, como consecuencia de dos fenómenos convergentes. Por un lado, el amplio desarrollo de la literatura sobre reglas fiscales contribuyó a generar una visión favorable sobre la conveniencia de sancionarlas. Este consenso favorable alcanzó a los organismos multilaterales de crédito, reflejándose en los listados de reformas estructurales sugeridas por el Fondo Monetario Internacional (FMI) y el Banco Mundial a los países con programas de asistencia y financiamiento.

\footnotetext{
${ }^{10}$ Versión de Espasa Calpe (Marx, 1992).

${ }^{11}$ Véase Makón (1997).
}

Simultáneamente, el deterioro de las condiciones financieras internacionales observado hacia finales de la década puso mayor presión sobre el desempeño de las economías emergentes, aumentando la preocupación por la evolución de las finanzas públicas y, muy especialmente, del endeudamiento.

En Argentina, el Congreso había sancionado legislación complementaria de la ley de administración financiera de 1992. La ley 24.629, promulgada en febrero de 1996, estableció restricciones al incremento de gastos sin financiamiento expreso, requisitos más exigentes de transparencia de las cuentas presupuestarias, y la obligación del Poder Ejecutivo de presentar al Congreso una vez por trimestre el estado de la ejecución presupuestaria y cada 30 de junio un informe de avance sobre el presupuesto del año siguiente. Como novedad, esta ley incluyó un tema característico del debate sobre las reglas fiscales: las penalidades por incumplimiento. De acuerdo con la nueva ley, la violación de las normas implicaba responsabilidad personal de los funcionarios involucrados frente a terceros.

\section{La ley de "convertibilidad fiscal"}

En 1998 comenzó a discutirse en el Congreso lo que luego se convertiría en la primera ley de responsabilidad fiscal en Argentina, la ley 25.152. Bautizada inicialmente como ley de administración de los recursos públicos, fue conocida públicamente como la ley de convertibilidad fiscal. ${ }^{12}$

La discusión del proyecto de ley en el Congreso demoró poco más de un año, período en el que el cambio abrupto de las condiciones macroeconómicas argentinas terminó influyendo significativamente en su contenido.

\footnotetext{
12 La popularidad que tenía entonces la "super regla" del régimen de convertibilidad indujo a los creadores de la nueva legislación fiscal a intentar una asociación forzada de su proyecto con el dispositivo cambiario/monetario que en 1991 había acabado con la inflación.
} 
En marzo de 1998, cuando fue presentado el proyecto original, ya aparecían los nubarrones de la crisis internacional que afectaría a las economías emergentes, pero la economía argentina venía de crecer un $8,1 \%$ en el año 1997 y un 6,5\% en la primera mitad de 1998. Un año después, tras el impacto de la crisis rusa y la devaluación brasileña, Argentina estaba en recesión, las presiones deflacionarias se hacían cada vez más explícitas, y la preocupación por la sustentabilidad de las cuentas públicas se extendía dentro y fuera del país. La robustez de la convertibilidad era puesta en tela de juicio y la cuestión fiscal aparecía como uno de sus eslabones más débiles. Con una economía que no podía crecer y con dificultades para acceder a financiamiento, el gobierno debía asegurar que ajustaría las cuentas en el futuro todo lo que fuera necesario, y la aprobación de la ley 25.152 era una buena oportunidad para hacerlo. ${ }^{13}$

Las reglas numéricas fueron el aspecto más conocido de dicha ley. Para el resultado financiero, la regla del proyecto original (un tope de $1 \%$ al déficit financiero) fue reemplazada por un cronograma de reducción gradual del déficit a partir de 1999, para llegar al equilibrio fiscal en el 2003. ${ }^{14} \mathrm{El}$ crecimiento del gasto público quedó supeditado al crecimiento del producto interno bruto (PIB), obligando a no aumentar el gasto primario corriente en el caso de caídas de la actividad económica. Se dispuso también la creación de un Fondo Anticíclico Fiscal (FAF), que se constituiría con ingresos extraordinarios provenientes de concesiones y privatizaciones y con un porcentaje definido de la recaudación de impuestos. ${ }^{15} \mathrm{El}$ proyecto original de la ley incluía también un artículo especial dedicado a las sanciones para quienes violasen sus disposiciones. Las penas estipuladas eran, sin embargo, las ya previstas para el delito de incumplimiento de los deberes de funcionario público, por lo que el artículo fue considerado

\footnotetext{
${ }^{13}$ En realidad, con la perspectiva de un cambio presidencial previsto para fines de 1999, el ajuste fiscal comprometido recaía en el gobierno siguiente, un detalle no menor para explicar el momento elegido para la votación.

${ }^{14}$ Luego de fijar un techo de 1,9\% del PIB para 1999, la ley estableció un procedimiento de reestimación del déficit de ese año, excluyendo ingresos excepcionales. Sobre la base de ese déficit reestimado, se estableció una reducción de $0,4 \%$ en el 2000 , de $0,5 \%$ en el 2001 y de $0,6 \%$ en el 2002, para llegar al equilibrio en el 2003.

${ }^{15}$ El FAF podía acumular recursos hasta un máximo de $3 \%$ del PIB, para ser utilizados durante la fase recesiva del ciclo económico. La propuesta original de De la Sota incluía un aporte inicial al FAF con las acciones del gobierno en empresas privatizadas. Dado que el grueso de esas acciones serían vendidas en los primeros meses de 1999, principalmente las acciones de la empresa Yacimientos Petrolíferos Fiscales (YPF), esos recursos desaparecieron en la versión final del Fondo Anticíclico.
}

redundante y quedó eliminado en la redacción final. La ley incluyó también algunas consideraciones sobre transparencia fiscal y reforma del Estado.

Como se mencionó en la sección anterior, las reglas fiscales suelen incluir cláusulas de escape que permitan evitar —o al menos amortiguar - el efecto procíclico que una regla rígida podría tener sobre la política fiscal, especialmente durante una recesión. El proyecto original de la ley 25.152 contenía una cláusula de escape que aceptaba el incumplimiento de los límites numéricos “...en casos de severa crisis internacional, catástrofe o emergencia interna determinada por el Poder Ejecutivo". Esta cláusula contingente, sin embargo, desapareció de la versión final de la ley. A mediados de 1999, las características del régimen de convertibilidad y la dificultad para conseguir financiamiento público hacían imposible pensar que Argentina pudiera ampliar su déficit fiscal como respuesta anticíclica a la recesión que afectaba a su economía. Por el contrario, todas las señales debían apuntar a confirmar el compromiso de las autoridades con el ajuste inmediato de las cuentas públicas, aun en un contexto macroeconómico adverso. Sin cláusula contingente, la regla forzaba no solo a eliminar el déficit fiscal incluso en períodos de recesión y deflación, sino también a formar un Fondo Anticíclico Fiscal con parte de los ingresos fiscales.

Los resultados de la ley 25. 152 fueron decepcionantes. Su entrada en vigor a principios de la década del 2000 coincidió con los fallidos intentos por evitar el desplome del régimen de convertibilidad, que fue finalmente abandonado a fines del 2001, en medio de una profunda crisis política, económica y social.

Los límites al déficit previstos en la ley fueron modificados en su primer año de vigencia y luego incumplidos. El tope al crecimiento del gasto se respetó en los años de recesión (cuando no había recursos para aumentar el gasto), pero no en los de recuperación. ${ }^{16} \mathrm{El}$ Fondo Anticíclico Fiscal llegó a constituirse, pero nunca tuvo recursos que le permitieran actuar en el sentido con el que fue concebido. Aunque la ley 25.152 nunca fue derogada formalmente, su rotundo fracaso inicial la llevó al olvido.

\section{La ley de "déficit cero"}

En la segunda mitad del 2001, pocos meses antes del desenlace de la crisis política y económica que derivó

\footnotetext{
${ }^{16}$ El gasto público total del sector público nacional creció de $15,8 \%$ del PIB en 2002 a 18,4\% en 2006, y el presupuesto 2007 lo proyecta en $19,19 \%$ del PIB. El gasto primario aumentó de $13,6 \%$ en 2002 a $16,3 \%$ en 2006.
} 
en el traumático abandono del régimen de convertibilidad, las autoridades ensayaron la puesta en práctica de una regla fiscal extrema, mucho más ambiciosa que la incumplida ley 25.152. La nueva regla, conocida públicamente como "ley de déficit cero" e instrumentada formalmente a través de una reforma a la Ley 24.156 de administración financiera, se propuso llevar a la práctica un principio muy simple: no gastar cada mes más que lo que podía financiarse con los recursos corrientes del Estado. ${ }^{17}$

Aunque sencilla en su concepción, la ley resultó absolutamente impracticable. El Poder Ejecutivo extendió a las jubilaciones y pensiones un recorte hasta ese momento aplicado solo a los salarios públicos, pero no alcanzó el tan mentado "déficit cero". Si bien la norma contemplaba incrementar el coeficiente de ajuste hasta equilibrar las cuentas, la inviabilidad política y social del esquema obligó a mantener el descuento sobre salarios y jubilaciones en el nivel inicial. Tiempo después, habiendo caído el régimen de convertibilidad, la ley de déficit cero sería declarada inconstitucional por la Corte Suprema de Justicia. ${ }^{18}$

La fugaz y estertórea vida de la extremista ley de déficit cero demostró de manera dramática que era inviable descargar todo el peso del ajuste de las cuentas públicas en una simple norma escrita. Como la ley 25.152, la ley de déficit cero pasó a engrosar el creciente listado de leyes incumplidas en Argentina. ${ }^{19}$

\section{IV}

\section{Una nueva ley de responsabilidad fiscal}

El interés público por la suerte de las reglas fiscales fue prácticamente nulo luego de la crisis de fines del 2001. La magnitud de los problemas que había que resolver (suspensión del pago de la deuda pública, reprogramación de depósitos bancarios, ruptura de contratos en los servicios públicos, alto desempleo) convertía el incumplimiento de las reglas aprobadas por ley en 1999 en un tema no prioritario, al que pocos prestaban atención. No se discutía el decepcionante desempeño de la ley 25.152 , y mucho menos se hablaba de su eventual reforma, ni en el Congreso ni en ámbitos del Poder Ejecutivo. La norma seguía vigente, pero sus prescripciones eran incumplidas,

\footnotetext{
${ }^{17}$ El texto siguiente fue incorporado al artículo 34 de la Ley 24.156 de administración financiera: "cuando los recursos presupuestarios estimados no fueren suficientes para atender la totalidad de los créditos presupuestarios previstos, se reducirán proporcionalmente los créditos correspondientes a la totalidad del Sector Público Nacional de modo de mantener el equilibrio entre gastos operativos y recursos presupuestarios. La reducción afectará los créditos destinados a atender el pago de retribuciones periódicas por cualquier concepto, incluyendo sueldos, haberes adicionales, asignaciones familiares, jubilaciones y pensiones, así como a aquellas transferencias que los organismos o entidades receptoras utilicen para el pago de dichos conceptos. La reducción de los créditos presupuestarios... importará de pleno derecho la reducción de las retribuciones alcanzadas, cualquiera que fuere su concepto, incluyendo sueldos, haberes adicionales, asignaciones familiares, jubilaciones y pensiones. Las reducciones de retribuciones se aplicarán proporcionalmente a toda la escala salarial o de haberes, según corresponda, sin discriminaciones de ningún tipo. Esta ley modifica en lo pertinente toda norma legal, reglamentaria o convencional que se le oponga y no se podrá alegar la existencia de derechos irrevocablemente adquiridos en su contra".
}

o dejadas en suspenso mediante artículos incluidos en las leyes de presupuesto de cada ejercicio. ${ }^{20}$

En el año 2004, sin embargo, el Congreso sancionó con el número 25.917 una nueva Ley de responsabilidad fiscal (LRF). El proyecto fue remitido por el Poder Ejecutivo al Congreso el 15 de junio de 2004, ingresando en la Cámara de Senadores. Menos de dos meses después, había sido aprobado por ambas cámaras del Congreso y era promulgado por el Poder Ejecutivo. Argentina tenía una nueva ley de responsabilidad fiscal.

Los contenidos de esta ley atendieron a varios objetivos. En materia de transparencia fiscal, se establecieron obligaciones de estandarizar, elaborar y difundir la información presupuestaria de la Nación y las provincias, con un horizonte plurianual. El gobierno

\footnotetext{
${ }^{18}$ En el fallo "Tobar contra el Estado Nacional", la Corte Suprema confirmó la inconstitucionalidad de la ley 25.453, argumentando que resultaba "...contrario a la Constitución Nacional un régimen normativo que difiere a la discrecionalidad del Poder Ejecutivo la determinación de remuneraciones y haberes previsionales, de naturaleza alimentaria, no como una alternativa de excepción susceptible de control jurisdiccional, sino como una herramienta de política económica, destinada circunstancialmente a la reducción del gasto público y estabilidad de las cuentas fiscales".

${ }^{19}$ La modificación introducida para establecer la regla del déficit cero fue eliminada de la ley 24.156 mediante un artículo de la ley de presupuesto del año 2003.

${ }^{20}$ La Secretaría de Hacienda incluyó en las leyes de presupuesto de los años 2003,2004, 2005 y 2006 artículos para dejar en suspenso la integración del Fondo Anticíclico Fiscal. Ver artículos 27 de la ley 25.565, 40 de la $25.827,30$ de la ley 25.967 y 24 de la ley 26.078 .
} 
nacional quedó encargado de presentar todos los años un marco macrofiscal que sería utilizado como insumo para elaborar el presupuesto de todas las jurisdicciones.

En lo que hace a reglas numéricas, la ley 25.917 fijó el crecimiento del PIB como límite a la expansión del gasto primario y prescribió la ejecución equilibrada del presupuesto una vez descontados ciertos gastos. ${ }^{21}$ Para las provincias, se estableció un límite al endeudamiento de forma tal que los servicios de la deuda no superasen el $15 \%$ de los recursos corrientes (deducidas las transferencias por coparticipación a municipios) de la jurisdicción. Todas las jurisdicciones fueron instadas a crear fondos fiscales de carácter anticíclico.

El gobierno nacional quedó facultado para concordar programas de financiamiento con las provincias que lo requiriesen, siempre y cuando se cumplieran las pautas definidas en la LRF. Se creó el Consejo Federal de Responsabilidad Fiscal, un organismo destinado a fiscalizar la aplicación de esta ley, integrado por representantes de la Nación y las provincias, y facultado para imponer sanciones por incumplimiento que iban desde la divulgación pública de los desvíos hasta la limitación de transferencias presupuestarias de origen nacional (excluida la coparticipación).

Varias disposiciones de la LRF repitieron limitaciones ya establecidas en la ley 25.152 , que no fue derogada, y en la ley 24.156 de administración financiera. Aunque sin el ajuste estipulado en la LRF, el límite al crecimiento del gasto público primario como proporción del PIB estaba presente en el artículo 2, inciso C, de la ley 25.152. La prohibición de amortizar deudas asociadas a gastos sin previo devengamiento presupuestario, establecida en el artículo 24 de la LRF, aparece en el artículo 3, inciso A, de la ley 25.152. Las limitaciones al Poder Ejecutivo para aumentar gastos corrientes en detrimento de gastos de capital y aplicaciones financieras durante la ejecución del presupuesto, estipuladas en el artículo 15 de la LRF, reiteran lo dispuesto por el artículo 37 de la ley 24.156. También se repitió la prohibición de crear fondos u organismos fuera del presupuesto y de las reglas generales de la administración financiera. El mandato del artículo 20 de la LRF para constituir un fondo anticíclico fiscal resulta sorprendente si tenemos en cuenta que desde hacía varios años funcionaba un fondo con esas características en el ámbito nacional, creado por la ley 25.152 .

\footnotetext{
${ }^{21}$ La regla alcanza a un gasto primario "ajustado", en el que se excluyen los gastos atados a financiamiento de organismos internacionales, y los gastos de capital destinados a infraestructura social básica. El mismo ajuste debe aplicarse para el cálculo del equilibrio financiero.
}

Además de reflejar cierta deficiencia en términos de técnica legislativa, el carácter redundante de varias de las disposiciones de la nueva LRF confirma otro fenómeno: una débil conexión de la nueva ley con una reflexión crítica respecto del desempeño de las reglas fiscales vigentes hasta ese momento. Teniendo un antecedente tan reciente y traumático en materia de reglas fiscales, era de esperar que la discusión de una nueva norma de responsabilidad fiscal se concentrara en las lecciones de la experiencia anterior, intentando distinguir al menos las causas de los incumplimientos. Entendidos de esa forma, los cambios en la legislación hubieran sido probablemente instrumentados a través de una reforma de las leyes existentes y no mediante la creación de una nueva norma. Sin embargo, la experiencia con la ley 25.152 no estuvo presente en la elaboración y debate parlamentario de la LRF, en cuyo texto no hay mención alguna a la ley anterior. Otros factores, vinculados a la coyuntura económica y política del año 2004, determinaron la génesis y los contenidos de la LRF.

\section{El Fondo Monetario Internacional, las provincias y la nueva ley de responsabilidad fiscal}

Dos fenómenos convergentes asociados a la coyuntura de la Argentina post-crisis sobresalen a la hora de explicar el proceso de sanción de la nueva LRF: las vicisitudes de la compleja relación de Argentina con el Fondo Monetario Internacional, y la asistencia financiera condicionada de la Nación a las provincias, que influyó fuertemente en los contenidos.

La dinámica de las relaciones entre Argentina y el FMI desempeñó un papel decisivo al momento de votarse una nueva regla fiscal. El programa de financiamiento del FMI a Argentina negociado en el 2001 por el ex ministro Domingo Cavallo concluyó abruptamente con la crisis desatada a finales de ese año. Luego de un acuerdo "corto" firmado por el presidente provisional Eduardo Duhalde en enero de 2003, en septiembre del mismo año el gobierno de Néstor Kirchner suscribió un acuerdo de derechos de giro (stand-by) a tres años, con desembolsos orientados a cubrir los vencimientos de la deuda argentina con el propio Fondo.

En la visión del FMI, la reforma fiscal — principalmente un nuevo régimen de coparticipación federal- debía ser uno de los ejes centrales del programa acordado. ${ }^{22}$ Dentro de las reformas estructurales que debían llevarse a cabo, el gobierno argentino se comprometía a enviar

\footnotetext{
22 Véanse las declaraciones de Anne Krueger en FMI (2003a).
} 
al Congreso dos proyectos de ley: una revisión de la ley de coparticipación de impuestos y nueva legislación sobre responsabilidad fiscal. El acuerdo establecía un cronograma preciso para las iniciativas: antes de marzo de 2004 se debía llegar a acuerdo con una "masa crítica" de gobernadores en torno a los principios de la legislación por aprobarse. ${ }^{23}$

En forma coherente con el análisis conceptual efectuado en la sección III, el FMI otorgaba una importancia primordial a la sanción de una nueva legislación fiscal que incluyese reglas. En la primera revisión del programa, realizada a fines de enero de 2004, las autoridades del Fondo aplaudieron el buen desempeño de las cuentas fiscales argentinas en el corto plazo, pero pusieron de relieve la necesidad de asegurar la sustentabilidad de la mejora fiscal mediante la reforma legislativa prometida. ${ }^{24}$

En la segunda revisión, realizada en marzo de 2004, el Fondo destacó la importancia que daba a los compromisos asumidos en materia de reforma fiscal:

"Además, se espera que haya progreso en pos de asegurar un consenso político en torno a la nueva legislación de responsabilidad fiscal y coparticipación. Estas son iniciativas críticas y las autoridades necesitan asegurar que las reformas que serán propuestas al Congreso provean una solución duradera a las debilidades del sistema actual - a saber, el insuficiente control sobre las finanzas provinciales, la falta de incentivos para aumentar la recaudación propia en ambos niveles de gobierno y la falta de equidad en la distribución de recursos entre provincias". (FMI, 2004a, pp. 12 y 14).

El Fondo seguía esperando el envío al Congreso de los dos proyectos de ley, el de reforma a la ley de coparticipación y la nueva ley de responsabilidad fiscal. Las metas estructurales revisadas del programa incluían un ambicioso cronograma: el ingreso de ambos proyectos en el Congreso antes del fin de mayo, y su aprobación en las legislaturas de la Nación y de las provincias antes del fin de agosto.

Pero la reforma a la coparticipación federal, la "madre de todas las batallas" en la discusión fiscal entre la Nación y las provincias, nunca llegó al Congreso. Con buen criterio, el gobierno nacional decidió no avanzar con

\footnotetext{
23 Véase FMI (2003b)

${ }^{24}$ FMI (2004b).
}

un proyecto legislativo que lo obligaba a una profunda negociación con las provincias en condiciones políticas que no garantizaban un resultado razonable. En ese contexto, el proyecto de nueva ley de responsabilidad fiscal se convirtió en una suerte de opción subóptima. Para el Fondo, porque podía presentar la sanción de la LRF como un avance en materia de reforma institucional en el plano fiscal. Para el gobierno, porque evitaba la caída del programa stand-by. Así, el Poder Ejecutivo presentó al Congreso el proyecto de LRF el 14 de junio de 2004, el mismo día en el que la misión del FMI comenzaba la tercera revisión del acuerdo firmado en septiembre del año anterior. ${ }^{25}$

La compleja relación fiscal y financiera entre la Nación y las provincias, cuyo tema dominante ha sido la postergada reforma al régimen de coparticipación federal, fue significativamente afectada por la crisis del 2001. Varias jurisdicciones habían expandido excesivamente sus gastos y deudas durante la bonanza, y exhibían enormes dificultades para adaptarse a un entorno menos favorable. Los compromisos financieros contraídos comprometían en algunos casos porciones demasiado grandes de los ingresos de las provincias. La asfixia de recursos y de financiamiento había llevado a muchas jurisdicciones a emitir cuasi monedas como único medio para efectuar los pagos básicos de la administración, esencialmente los salarios de los empleados públicos.

En febrero del 2002, el nuevo gobierno nacional había alcanzado un acuerdo fiscal con las provincias, dirigido a resolver los aspectos más críticos de la coyuntura. ${ }^{26}$ Las deudas provinciales fueron asumidas por la Nación y renegociadas a plazos largos y tasas de interés menores, y el reparto de los ingresos por coparticipación volvió a realizarse con los coeficientes definidos por la legislación. Las jurisdicciones con mayores dificultades en materia fiscal y financiera se comprometieron a reducir sus desequilibrios y a no incrementar su endeudamiento, a cambio de ayuda financiera del gobierno federal, en el marco de acuerdos bilaterales con la Nación conocidos como Programas de Financiamiento Ordenado (PFO). ${ }^{27}$

\footnotetext{
${ }^{25}$ La tercera revisión nunca llegó a completarse, y el programa stand-by quedó suspendido. El Fondo se manifestó en desacuerdo con varias "debilidades" de la nueva legislación sobre responsabilidad fiscal (FMI, 2005).

${ }^{26}$ Acuerdo Nación-Provincias sobre Relación Financiera y Bases de un Régimen de Coparticipación Federal de Impuestos, celebrado el 27 de febrero del 2002 y ratificado por la Ley Nacional $\mathrm{N}^{\mathrm{o}} 25.570$.

${ }^{27}$ Mediante Decreto del Poder Ejecutivo Nacional No 2.263 , fechado el 8 de noviembre de 2002, se creó formalmente el Programa de Financiamiento Ordenado de las Finanzas Provinciales, destinado a los estados provinciales y a la ciudad autónoma de Buenos Aires,
} 
Los PFO incluían financiamiento de la Nación para encarar el déficit y las amortizaciones de deuda, a cambio de metas provinciales de reducción del desequilibrio fiscal mediante la racionalización del gasto y el aumento de la recaudación, el no incremento de la deuda ni de las cuasi monedas, y la realización de reformas en materia de transparencia fiscal y administración financiera. Para garantizar el reembolso de los préstamos recibidos, las provincias aceptaban ceder a la Nación los derechos a recursos de la coparticipación federal de impuestos. Los acuerdos establecían penalidades para el caso de incumplimiento por parte de las provincias. ${ }^{28}$

Hubo una fuerte influencia de los Programas de Financiamiento Ordenado en los contenidos de la LRF del año 2004, que se convirtió en instrumento para dar un soporte institucional mayor a los acuerdos bilaterales de financiamiento entre la Nación y las provincias. ${ }^{29} \mathrm{Con}$ base en el artículo 26 de dicha ley, la Nación continuó firmando acuerdos con algunas provincias e incluso utilizando el mismo vehículo financiero, el Fondo Fiduciario de Desarrollo Provincial (FFDP). ${ }^{30}$ La LRF comparte con los Programas de Financiamiento Ordenado el objetivo de poner un límite al nivel de deuda pública de las provincias, y en ambos instrumentos se fijaron penalidades similares para los incumplimientos. La mayor parte de los requisitos en materia de gestión y transparencia fiscal presentes en los PFO aparecieron luego en la redacción de la LRF. El rol de coordinación y fiscalización, que en los PFO era ejercido por la Subsecretaría de las Relaciones con Provincias, se transfirió al Consejo de Responsabilidad Fiscal creado por la nueva legislación.

mediante el cual el Estado nacional asiste financieramente a dichas jurisdicciones.

${ }^{28}$ La Nación suscribió PFO con 17 provincias en el año 2002, otorgando financiamiento por 2.730 millones de pesos para cubrir necesidades de caja y pagos de amortizaciones de la deuda pública. Sobre bases similares, volvieron a firmarse PFO en el 2003 (con un financiamiento comprometido de la Nación que superó los 3.000 millones de pesos) y en el 2004 (Cetrángolo y Jiménez, 2004).

${ }_{29}$ El Ministro de Economía Roberto Lavagna confirmó públicamente la conexión entre la nueva ley y los Programas de Financiamiento Ordenado (PFO). "Creemos que es conveniente reflejar buena parte de la experiencia de estos últimos tres años en una ley que tenga un carácter más permanente. Esta ley tiene la idea de que todos, Nación y provincias, trabajemos con normas y proyecciones macroeconómicas comunes, que haya normas de transparencia y de coordinación" (Lavagna, 2004).

${ }^{30}$ El FFDP, creado por decreto en 1995 para apoyar reformas en los estados provinciales, comenzó a ser utilizado por la Nación como instrumento de financiamiento de las provincias en los años 2000 y 2001. El FFDP fue también el medio para transferir los recursos comprometidos por los PFO en el 2002, el 2003 y el 2004, con fondos aportados por la Tesorería. En los últimos años, el FFDP ha sido el instrumento a través del cual se ha implementado la asistencia a las provincias previsto en la LRF.
El tema Nación-provincias impregnó los contenidos de la LRF, pero no parece haber sido determinante del momento en que se aprobó la nueva legislación. Cabe especular con que, de no mediar la presión del Fondo para que se aprobara la LRF, la asistencia financiera a las provincias hubiera continuado siendo administrada a través de los PFO.

\section{La vigencia de la ley de responsabilidad fiscal (LRF) del 2004}

Los primeros pasos de esta nueva ley arrojan luces y sombras. Con ingresos públicos que crecen a la par con la actividad económica, Argentina ha logrado mejorar significativamente sus cuentas fiscales en los últimos años. Pero durante el ejercicio fiscal 2005, el primero afectado por la LRF, la Nación no cumplió con la regla numérica más importante de la nueva norma: el gasto primario ajustado creció a un ritmo superior al del PIB. ${ }^{31}$

En las provincias, el Consejo Federal de Responsabilidad Fiscal encontró que durante el 2005 se cumplieron las pautas de resultado equilibrado y de gasto, aunque algunas jurisdicciones superaron los límites de endeudamiento. ${ }^{32}$ Hacia el futuro, el Poder Ejecutivo impulsa un cambio en la forma de medir los límites al incremento del gasto en las provincias, mediante el cual a partir del 2007 se excluirían los gastos con asignación específica financiados con aportes no automáticos del gobierno federal. Con esta modificación, la LRF quedaría completamente desnaturalizada. ${ }^{33}$

Los límites a las modificaciones que el Poder Ejecutivo puede hacer al presupuesto durante su ejecución, previstos en el artículo 15 de la LRF, fueron suspendidos transitoriamente por un artículo de la ley de presupuesto 2005 votada pocos meses después de sancionada esta ley, y en forma permanente mediante una polémica reforma a la Ley de administración financiera sancionada a mediados del $2006 .{ }^{34}$

No ha habido mejoras, al menos por parte de la Nación, en la meta de consolidar en el presupuesto todos

\footnotetext{
${ }^{31}$ Véase ASAP (2005).

32 Véase Consejo Federal de Responsabilidad Fiscal (2006).

${ }^{33} \mathrm{El}$ cambio se ha incluido en el artículo 20 del proyecto de ley de presupuesto 2007 presentado al Congreso. El esquema introduce incentivos perversos: las provincias quedarían limitadas para aumentar el gasto financiado con sus propios recursos (o con su porción de la coparticipación de impuestos), pero podrían aumentarlo si lo financian con transferencias discrecionales del gobierno central.

${ }^{34}$ Se trata de la ley 26.124 de agosto del 2006, que corrigió el artículo 37 de la ley 24.156, ampliando las facultades del Poder Ejecutivo para modificar durante la ejecución el presupuesto votado por el Congreso.
} 
los entes y/o fondos que hoy están fuera de las normas presupuestarias. $^{35}$

La difusión pública de información fiscal prevista en el artículo $7^{\circ}$ de la ley no ha mejorado. En el caso del sector público nacional, la información sobre la ejecución presupuestaria, la deuda pública y la deuda flotante de la Tesorería muestra un rezago que es superior al trimestre exigido por la LRF. Tampoco está disponible la información de ocupación y empleo. El Consejo Federal de Responsabilidad Fiscal ha comenzado a publicar información de las provincias, pero en forma parcial y con importantes rezagos.

En contradicción con lo dispuesto por el artículo 13 de la ley señalada, fueron creados nuevos fondos asociados a gastos que no se consolidan en el presupuesto general.

\section{V}

\section{Conclusiones}

En Argentina, la prodigalidad en el uso de reglas fiscales - dos leyes distintas en tan solo cinco años- contrasta con los escasos resultados obtenidos. Las reglas han demostrado muy baja capacidad para asegurar la sustentabilidad de la política fiscal, mejorar la transparencia y desterrar la colección de malas prácticas que han dominado durante años en el proceso presupuestario argentino.

El rápido y generalizado incumplimiento de las reglas contenidas en la primera ley de responsabilidad fiscal sancionada en Argentina — la ley 25.152 de 1999, conocida como ley de convertibilidad fiscal- estuvo en gran medida asociado a la crisis macroeconómica que estalló a fines de 2001. Cinco años después, sin embargo, con un escenario económico sumamente favorable, las disposiciones de la ley de responsabilidad fiscal de 2004, muchas de ellas ya presentes en la norma anterior, muestran también bajos niveles de cumplimiento. La mejora en los indicadores macrofiscales de Argentina observada después de la crisis del 2001 responde a un conjunto de factores convergentes (nuevos impuestos, crecimiento acelerado e inflación, reestructuración de

\footnotetext{
${ }^{35}$ En su artículo $3^{\circ}$, la LRF otorgó un plazo de dos años para que dichos fondos y entes volvieran a incorporarse al presupuesto general. En el proyecto de presupuesto 2007, dichos fondos y entes no han sido reincorporados, pero se le agregó un artículo pidiendo un "cronograma de actividades que contemple la finalización de ese proceso de inclusión".
}

No se respetó el artículo 17, que dispone la obligación de compensar cualquier medida tributaria que lleve a una menor recaudación con aumentos de recursos o con reducción de gastos. ${ }^{36}$

En síntesis, un balance preliminar del cumplimiento de las reglas establecidas en la LRF arroja un resultado poco auspicioso, que la emparenta con su antecesora, la ley 25.152 de los primeros años de la década. Pese al extremo contraste en el marco macroeconómico existente en el momento en que cada una de ellas entró en vigencia (muy adverso para la 25.152, favorable para la LRF), ambos casos muestran una escasa preocupación del gobierno (y de la opinión pública en general) sobre el apego a las reglas allí establecidas.

la deuda pública), y no puede atribuirse a la sanción de la LRF de 2004. Como proporción del PIB, el resultado fiscal primario nacional en el 2005 cayó más de un 1\% con respecto al año anterior y, como se mencionó antes, no se respetó la regla más importante para un período de expansión como el que vive Argentina: la de limitar el crecimiento del gasto. ${ }^{37}$

En contextos de debilidad institucional como el argentino, en donde el Poder Ejecutivo modifica las leyes con frecuencia y facilidad sorprendentes, cuesta imaginar que una ley de responsabilidad fiscal pueda limitar en forma significativa las decisiones de los gobernantes, al punto de corregir el patrón de comportamiento de las finanzas públicas. ${ }^{38}$

Como se mencionó en la sección II, algunos autores han señalado que quizás la gran virtud de las leyes de responsabilidad fiscal sea simplemente la de convertirse en

\footnotetext{
${ }^{36}$ A mediados de marzo del 2006, el Poder Ejecutivo dispuso una modificación en la normativa de mínimos no imponibles del impuesto a las ganancias, sin presentar medida compensatoria alguna.

${ }^{37}$ El resultado primario bajó de 4,04\% del PIB en el 2004 a 2,98\% en el 2005. El resultado financiero cayó de $2,6 \%$ a $0,68 \%$ en el mismo período.

${ }^{38}$ Eifert, Gelb y Borje (2002) han estudiado el uso de fondos de estabilización y otras reformas presupuestarias en distintos países con abundantes recursos petroleros, y han concluido que en los países considerados "democracias facciosas" (categoría que incluiría a Argentina y otros países de la región) estos esquemas no funcionan adecuadamente si no cuentan con un fuerte apoyo político.
} 
vehículos para que las sociedades construyan consensos políticos en torno a la necesidad de asegurar la solvencia del sector público. En América Latina, la experiencia de Chile al respecto es ilustrativa: el sector público chileno ya cumplía con la meta de superávit fiscal estructural del $1 \%$ del PIB varios años antes de que ella fuera anunciada como regla. ${ }^{39}$

En Argentina, la discusión parlamentaria de los proyectos de ley de responsabilidad fiscal no ha estado vinculada a una discusión pública de fondo sobre la importancia de la disciplina fiscal. Pese a la traumática experiencia anterior, la discusión de la LRF demoró menos de dos meses en el Congreso, y no fue acompañada de reflexiones y/o debates sobre el tema en otros ámbitos cercanos a las finanzas públicas.

Lejos de pensarlas como herramientas para regular la política fiscal de largo plazo, las reglas han sido utilizadas como instrumentos para responder a necesidades de corto plazo, con evidente despreocupación por su desempeño posterior. En 1999, la redacción de la ley 25.152 llevaba al extremo la idea de la "regla fiscal como señal" (Drazen, 2002), buscando transmitir un compromiso sin fisuras de las autoridades con el régimen de convertibilidad.

Pero en el año 2004 parecía ingenuo suponer que la sanción de una nueva ley de responsabilidad fiscal podía convertirse en una señal positiva sobre el compromiso fiscal de las autoridades. Con la deuda pública en suspensión de pagos, la reputación del fisco argentino se encontraba muy disminuida, y difícilmente podía mejorar con una nueva ley del Congreso que prometía, una vez más, un comportamiento fiscalmente disciplinado.

¿Cómo explicar entonces la aprobación de la LRF? Pese a su nula potencialidad como "señal", la ley resultó útil para otros objetivos de la coyuntura, principalmente la viabilidad del acuerdo stand-by entonces vigente entre Argentina y el FMI. El Fondo mantenía su recurrente presión para lograr que se aprobaran las reformas estructurales, en particular en el plano fiscal, pero las autoridades argentinas advirtieron la inconveniencia de forzar el debate sobre la reforma del régimen de coparticipación de impuestos. Conseguir una ley de responsabilidad fiscal, bien ponderada en los círculos académicos y en los organismos multilaterales, se convirtió en una salida honrosa para Argentina y para los negociadores del FMI. Desde la perspectiva argentina, la sanción de la nueva Ley de responsabilidad fiscal resultaba positiva si ayudaba a darle viabilidad al programa con el FMI y servía además para institucionalizar los programas de asistencia financiera bilateral con las provincias, los antiguos Programas de Financiamiento Ordenado.

Hacia el futuro, el análisis de lo sucedido nos lleva a la paradójica recomendación de que Argentina reabra una vez más el debate legislativo sobre responsabilidad fiscal. El desorden de la legislación vigente hace necesario consolidar y ordenar las normas, probablemente en un único cuerpo legal. No se trata de elaborar una tercera regla fiscal para atender alguna situación coyuntural o los deseos de algún organismo multilateral, sino de racionalizar la legislación existente, depurándola de cuestiones redundantes o de objetivos difícilmente alcanzables.

Esa racionalización de la normativa de responsabilidad fiscal podría ser aprovechada para generar un amplio debate público sobre las ventajas de la disciplina fiscal y las buenas prácticas presupuestarias, involucrando a todos los sectores políticos y sociales interesados en la materia. Aunque resulte menos ambiciosa en lo formal, una revisión de la legislación fiscal que lleve a la sociedad a construir un consenso en torno al tema tendrá seguramente efectos mucho más beneficiosos sobre el desempeño de las cuentas públicas.

En el plano regional, la experiencia argentina debería ser también un llamado de atención para los organismos multilaterales, que con facilidad incluyen la sanción de una regla fiscal dentro de las condiciones establecidas en los programas de asistencia. En países con baja reputación fiscal e institucionalidad débil, no solo las reglas pueden resultar completamente ineficaces en materia fiscal, sino que su incumplimiento puede contribuir a deteriorar más el frágil entorno institucional que dificulta su eficacia. ${ }^{40}$ Quizás son los organismos multilaterales los que deberían cumplir con una nueva regla: no impulsar la sanción de reglas fiscales en países que solo las establecen para obtener el financiamiento que tales organismos ofrecen.

\footnotetext{
${ }^{39}$ La regla chilena tiene otra característica llamativa que contrasta con las recomendaciones de la literatura: no está basada en instrumento normativo alguno de orden legal o constitucional. Véase al respecto Marcel (2006) y Vial (2003).
}

${ }^{40}$ Vial (2003) examina los problemas surgidos en la implementación de
leyes sobre reglas fiscales impulsada por el FMI en Perú y Ecuador. 
Bibliografía

Alesina, A. y R. Perotti (1996): Fiscal discipline and the budget process, American Economic Review, vol. 86, No 2, Nashville, Tennessee, American Economic Association, mayo.

ASAP (Asociación Argentina de Presupuesto y Administración Financiera Pública) (2005): Informe de ejecución, IV trimestre del 2005, Buenos Aires.

Braun, M. y M. Tommasi (2004): Subnational fiscal rules: a game theoretic approach, en G. Kopits (comp.), Rules-Based Fiscal Policy in Emerging Markets: Background, Analysis and Prospects, Houndmills, Palgrave Macmillan.

Cetrángolo, O. y J.P. Jiménez (2004): Las relaciones entre niveles de gobierno en Argentina: raíces históricas, instituciones y conflictos persistentes, serie Gestión pública, No 47, LC/L.2201-P, Santiago de Chile, Comisión Económica para América Latina y el Caribe (CEPAL). Publicación de las Naciones Unidas, $\mathrm{N}^{\circ} \mathrm{de}$ venta: S.04.II.G.126.

Consejo Federal de Responsabilidad Fiscal (2006): Evaluación del cumplimiento: Régimen Federal de Responsabilidad Fiscal. Ejercicio 2005, Buenos Aires, junio.

Cukierman, A. (1992): Central Bank Strategy, Credibility and Independence: Theory and Evidence, Cambridge, Massachusetts, The MIT Press.

Drazen, A. (2002): Political Economy in Macroeconomics, Princeton, Princeton University Press.

Drazen, A. y A. Brender (2005): Political budget cycles in new versus established democracies, Journal of Monetary Economics, vol. 52, $\mathrm{N}^{\circ} 7$, Amsterdam, Elsevier, octubre.

Eifert, B., A. Gelb y N. Borje (2002): The Political Economy of Fiscal Policy and Economic Management in Oil Exporting Countries, Policy Research Working Paper, No 2899, Washington, D.C., Fondo Monetario Internacional.

FMI (Fondo Monetario Internacional) (2005): Argentina: 2005 Article IV Consultation: Staff Report, IMF Country Report, $\mathrm{N}^{\circ}$ 05/236, Washington, D.C.

(2004a): Argentina: Second Review under the Stand-By Arrangement and Requests for Modification and Waiver of Performance Criteria-Staff Report, IMF Staff Country Reports, $\mathrm{N}^{\mathrm{o}} 195$, Washington, D.C., julio.

(2004b): Press Release, $N^{\circ}$ 04/16, Washington, D.C., 28 de enero.

(2003a): Press Release, № 03/160, Washington, D.C., 20 de septiembre.

(2003b): Argentina: Request for Stand-By Arrangement and Request for Extension of Repurchase Expectations, IMF Staff Country Reports, No 03/392, Washington, D.C., 19 de diciembre.

Gadano, N. (2003): Rompiendo las reglas: Argentina y la Ley de Responsabilidad Fiscal, Desarrollo económico, No 170 , Buenos Aires, Instituto de Desarrollo Económico y Social (IDES), julio-septiembre.

Homero (1987): Canto XII, La Odisea, Madrid, Ed. Akal.
Kopits, G. (2001): Fiscal Rules: Useful Policy Framework or Unnecessary Ornament?, IMF Working Paper, $\mathrm{N}^{\circ} 01 / 145$, Washington, D.C., Fondo Monetario Internacional, octubre.

Kopits, G. y S. Symansky (1998): Fiscal Policy Rules, IMF Occasional Paper, No 162, Washington, D.C., Fondo Monetario Internacional.

Kydland, F. y E. Prescott (1977): Rules rather than discretion: the inconsistency of optimal plans, The Journal of Political Economy, vol. 85, $\mathrm{N}^{\circ}$ 3, Chicago, The University of Chicago Press, junio.

Lavagna, R. (2004): Hay 13 programas de financiamiento vigentes, La Nación, Buenos Aires, 15 de junio.

Makón, M. (1997): La reforma del sistema presupuestario nacional, Revista ASAP, $\mathrm{N}^{\circ} 29$, Buenos Aires, Asociación Argentina de Presupuesto y Administración Financiera Pública, abril.

Marcel, M. (2006): Cinco años de balance estructural en Chile: una evaluación, presentación en el Seminario Regional de Política Fiscal (Santiago de Chile, 23 al 26 de enero).

Marx, K. (1992): El dieciocho brumario de Luis Bonaparte, Madrid, Espasa Calpe.

Milesi-Ferretti, G. (2000): Good, Bad or Ugly? On the Effects of Fiscal Rules with Creative Accounting, IMF Working Paper, $\mathrm{N}^{\circ} 172$, Washington, D.C., Fondo Monetario International.

Persson, T. y G. Tabellini (2000): Political Economics: Explaining Economic Policy, Cambridge, Massachusetts, The MIT Press.

Schick, A. (2002): Budget Rules versus Political Will, documento preparado para la Conferencias del Fondo Monetario Internacional y el Banco Mundial sobre Reglas Macro-Fiscales en Economías de Mercados Emergentes (Oaxaca, México, 14 al 16 de febrero).

Tabellini, G. y A. Alesina (1988): Voting on the Budget Deficit, UCLA Working Paper, $N^{\circ}$ 539, Los Angeles, California, Universidad de California, diciembre.

Ter-Minassian, T. (2006): Enhancing Fiscal Discipline Over the Cycle, documento presentado en el Seminario Regional de Política Fiscal (Santiago de Chile, enero de 2006).

Tommasi, M. (1998): Instituciones y resultados fiscales, Desarrollo económico, vol. 38, $\mathrm{N}^{\circ}$ 149, Buenos Aires, Instituto de Desarrollo Económico y Social (IDES).

Velasco, A. (1999): A model of endogenous fiscal deficits and delayed fiscal reforms, en J. Poterba y J. von Hagen (comps.), Fiscal Institutions and Fiscal Performance, NBER Working Paper, $N^{\circ}$ 6336, Cambridge, Massachusetts, National Bureau of Economic Research.

Vial, J. (2003): Política fiscal en un contexto de elevada volatilidad externa, Caracas, Corporación Andina de Fomento (CAF).

Weingast, B.R., K.A. Shepsle y C. Johnsen (1981): The political economy of benefits and costs: a neoclassical approach to distributive politics, The Journal of Political Economy, vol. 89, $\mathrm{N}^{\mathrm{o}} 4$, Chicago, University of Chicago Press. 